\title{
Histopathological evaluation of ulcerative colitis in colonoscopic biopsies
}

\author{
Dhakhwa $\mathrm{R}^{1}$, Shrestha $\mathrm{HG}^{2}$, Acharya $\mathrm{IL}^{3}$ \\ ${ }^{I}$ Department of Pathology, Kathmandu Medical College, Kathmandu, Nepal \\ ${ }^{2}$ Department of Pathology, Kathmandu Hospital Private Limited, Kathmandu, Nepal \\ ${ }^{3}$ Department of Medicine, Kathmandu Hospital Private Limited, Kathmandu, Nepal
}

\section{Keywords: \\ Cryptitis; \\ Backwash ileitis; \\ Basal plasmacytosis; \\ Inflammatory Bowel \\ Disease}

\begin{abstract}
Background: Histopathologic evaluation of colonoscopic mucosal biopsy remains one of the earliest modalities of investigation in patients clinically suspected of ulcerative colitis. Pathologists should be aware of classical histomorphological features to avoid misdiagnosis. The aim of the present study was to evaluate histopathologic features as well as to determine possible atypical presentation.
\end{abstract}

Materials and Methods: Forty newly diagnosed cases of ulcerative colitis were included in the study. Colonoscopic biopsies taken from rectum as well as various areas of colon and ileum depending upon clinical extent of involvement were submitted for histopathological evaluation. Diagnosis of ulcerative colitis was made by correlating clinical, endoscopic and histopathologic findings.

Results: Out of 47 cases suspected of ulcerative colitis, histopathologic features were consistent with Ulcerative colitis in 40 cases. Almost all cases (97.5\%) showed diffuse active colitis. Cryptitis (100\%), crypt abscesses (75\%) and basal plasmacytosis (85\%) along with crypt architectural abnormalities (75\%) and goblet cell depletion (70\%) were classical histological changes associated with ulcerative colitis in active phase. Atypical presentations noticed were focal active colitis (2.5\%), backwash ileitis (2.5\%), rectal sparing (2.5\%) and skip areas (5\%).

Conclusion: Accurate diagnosis of ulcerative colitis requires elaborate knowledge of histopathologic features along with awareness of possible atypical presentation.

\section{INTRODUCTION}

Ulcerative colitis (UC) is an inflammatory bowel disease (IBD) of unknown cause. ${ }^{1}$ A precise diagnosis of UC is of paramount importance for appropriate treatment. The diagnosis of IBD requires a multidisciplinary approach involving a team of specialists (eg, gastroenterologists,

\section{Correspondence:}

Dr. Ramesh Dhakhwa, MD

Kathmandu Medical College and Kathmandu Hospital Pvt. Ltd.,

Kathmandu, Nepal

Email:rdhakhwa@gmail.com pathologists and radiologists). The diagnosis should be established by a combination of medical history, clinical evaluation, laboratory data (including negative stool examinations for infectious agents) and typical endoscopic, histologic and radiologic findings. Histologic examination of endoscopic biopsies remains a key step in the workup of affected patients and can be used for diagnosis and differential diagnosis, particularly in the differentiation of UC from Crohn's disease (CD) and other non-IBD related colitides. ${ }^{2}$ One of the earliest mode of histological 


\begin{tabular}{|c|c|c|}
\hline Extent of bowel involvement & $\begin{array}{l}\text { Number } \\
\text { of cases }\end{array}$ & $\begin{array}{l}\% \text { of } \\
\text { cases }\end{array}$ \\
\hline Left sided disease with rectal involvement & 22 & 55 \\
\hline Left sided disease with rectal sparing & 1 & 2.5 \\
\hline Rectal involvement only & 11 & 27.5 \\
\hline $\begin{array}{l}\text { Continuous left sided disease with right side } \\
\text { involvement }\end{array}$ & 3 & 7.5 \\
\hline $\begin{array}{l}\text { Continuous left sided disease with skip areas } \\
\text { on right side }\end{array}$ & 2 & 5 \\
\hline Pan colitis with backwash ileitis & 1 & 2.5 \\
\hline
\end{tabular}

evaluation is colonoscopic mucosal biopsy. Biopsies also allow assessment of disease activity and identification of pre-cancerous lesions and cancer. ${ }^{1}$ Accurate diagnosis requires knowledge of classic morphological features; pathologists should however be aware of the atypical pathologic presentation as well to prevent misdiagnosis. ${ }^{3}$ Hence the purpose of our study was to evaluate classic histopathologic features as well as to determine atypical presentations of Ulcerative colitis.

\section{MATERIALS AND METHODS}

Forty seven new cases suspected of ulcerative colitis clinically and/ or endoscopically undergoing colonoscopic biopsies at Pathology departments of Kathmandu Hospital Private limited and Kathmandu Medical College- Teaching Hospital from June 2013 to May 2015 were included in the study. Already diagnosed cases and patients who had taken specific medications for colitis or coexisting disease were excluded from the study. Detailed endoscopic findings, extent of disease, clinical disease severity were recorded. Colonoscopic biopsies were taken from rectum as well as various areas of colon depending upon the clinical extent of involvement. Biopsy from terminal ileum was also taken where applicable. Biopsy tissue was immediately fixed in $10 \%$ Formalin, processed routinely and stained with Hematoxylin and Eosin stain. Histopathologic parameters assessed were pattern of inflammation, crypt architectural abnormalities, goblet cell depletion, types of inflammatory cells in the lamina propria, basal plasmacytosis and activity (cryptitis and crypt abscesses). The slides were also analysed for presence of dysplasia or any unusual histopathologic features. Statistical analysis was performed using Epi-info wherever necessary.

\section{RESULTS}

Out of 47 cases suspected of ulcerative colitis, histopathologic features were consistent with Ulcerative colitis in active phase in 40 cases. Seven cases which showed non-specific inflammatory changes were excluded from the study. Diffuse active colitis, crypt architectural abnormalities with loss of goblet cells and basal plasmacytosis were considered to be the typical histologic features associated with ulcerative colitis.

Most of the patients were between $21-40$ years of age, the youngest being 21 years and the eldest was 71 years of age. All patients presented with a history of bleeding PR. Most of them also had complains of diarrhoea with passage of stool mixed with mucus ( 25 cases, $62.5 \%$ ). Some patients had constipation (7 cases, $17.5 \%)$ and abdominal pain (5 cases, $12.5 \%$ ) while others had non-specific symptoms (3 cases, $7.5 \%$ ). These symptoms were present for few days to few years. All patients underwent colonoscopy with biopsy. Colonoscopy revealed left sided colitis with rectal involvement in 22 cases (55\%). Eleven cases $(27.5 \%)$ showed rectal involvement only. Rectal sparing was observed in 1 case $(2.5 \%)$. Continuous left sided disease with right side involvement was noted in three cases (7.5\%) while skip areas were observed on right side in two cases $(5 \%)$. One case presented with pancolitis with backwash ileitis (2.5\%). (Table 1; fig. 1)

Among the forty cases, $26(65 \%)$ had mild colitis, eight $(20 \%)$ had moderate colitis and six $(15 \%)$ had colitis of severe degree endoscopically. Pseudopolyps were noted in four $(10 \%)$ of these cases.

Histologic evaluation revealed diffuse active colitis in almost all cases (39 cases, 97.5\%) except one (2.5\%) which showed focal active colitis. 15 cases (37.5\%) showed mild distortion of crypt architecture while 13 (32.5\%) showed moderate distortion and two cases $(5 \%)$ showed marked distortion with crypt atrophy. In 10 cases (25\%) crypt architecture appeared normal. Goblet cell depletion was noted in 28 cases $(70 \%)$. The predominant cells in the lamina propria were lymphocytes and plasma cells. Basal plasmacytosis (fig. 2) was present in 34 cases $(85 \%)$. Lymphoid follicles were observed in 10 cases $(25 \%)$. Eosinophils were prominent in 27 cases (67.5\%). Cryptitis was present in all cases (100\%) whereas crypt abscesses (fig. 3) were detected in only 30 cases (75\%). Muscularis mucosal hypertrophy was appreciated in 8 cases $(20 \%)$. Low grade dysplasia was present in one case $(2.5 \%)$. None of the cases had invasive carcinoma. (Table. 2)

\section{DISCUSSION}

The histologic diagnosis of IBD is based on analysis of a full series of colonoscopic biopsies. A study by Dejaco et al. showed that the accuracy of diagnosing colitis increases from $66 \%$ to $92 \%$ when segmental biopsies are taken rather than two biopsies throughout the colon. ${ }^{4}$ Rectal biopsies are necessary to either confirm or reject rectal involvement and may be additionally helpful in differentiating IBD from other inflammatory lesions. ${ }^{2}$

All tissue samples should be fixed immediately by immersion 
Table 2: Histopathologic features of Ulcerative colitis

\begin{tabular}{|c|c|c|}
\hline Histopathologic features & Number of cases & $\%$ of cases \\
\hline \multicolumn{3}{|l|}{ Crypt architecture } \\
\hline Normal & 10 & 25 \\
\hline Mild distortion & 15 & 37.5 \\
\hline Moderate distortion & 13 & 32.5 \\
\hline Marked distortion & 2 & 5 \\
\hline \multicolumn{3}{|l|}{ Goblet cells } \\
\hline Depleted & 28 & 70 \\
\hline Preserved & 12 & 30 \\
\hline \multicolumn{3}{|l|}{ Basal plasmacytosis } \\
\hline Present & 34 & 85 \\
\hline Absent & 6 & 15 \\
\hline \multicolumn{3}{|l|}{ Cryptitis } \\
\hline Present & 40 & 100 \\
\hline Absent & 0 & 0 \\
\hline \multicolumn{3}{|l|}{ Crypt abscesses } \\
\hline Present & 30 & 75 \\
\hline Absent & 10 & 25 \\
\hline \multicolumn{3}{|l|}{ Eosinophilic infiltrate } \\
\hline Prominent & 27 & 67.5 \\
\hline Not prominent & 13 & 32.5 \\
\hline \multicolumn{3}{|l|}{ Lymphoid follicles } \\
\hline Present & 10 & 25 \\
\hline Absent & 30 & 75 \\
\hline \multicolumn{3}{|c|}{ Muscularis mucosal hypertrophy } \\
\hline Present & 8 & 20 \\
\hline Absent & 32 & 80 \\
\hline \multicolumn{3}{|l|}{ Pseudopolyps } \\
\hline Present & 4 & 10 \\
\hline Absent & 36 & 90 \\
\hline \multicolumn{3}{|l|}{ Dysplasia } \\
\hline Low grade & 1 & 2.5 \\
\hline High grade & 0 & 0 \\
\hline Absent & 39 & 97.5 \\
\hline
\end{tabular}

in buffered formalin or an equivalent solution prior to transport. Serial sectioning of biopsy specimens is superior to step sectioning in order to detect mild or focal lesion and to increase the diagnostic accuracy. ${ }^{5-7}$ The diagnostic yield increases with the number of sections examined. However the ideal number of sections to be examined in routine practice has not been established with numbers varying between 2 and 6 in different studies. ${ }^{6,8}$

Ulcerative colitis classically shows a diffuse and continuous chronic inflammation without skip areas which involves the rectum and spreads proximally with gradually decreasing severity of inflammation. Unusual inflammation patterns are rectal sparing, caecal patch and backwash ileitis. ${ }^{2}$ Our study also demonstrated one case $(2.5 \%)$ of rectal sparing, one $(2.5 \%)$ with backwash ileitis and two (5\%) with skip lesions. Although rectal sparing and patchy disease suggest diagnosis of Crohn's disease, the cases included in our study showed diffuse active colitis on histology favoring ulcerative colitis. Many studies have attributed rectal sparing and skip lesions to either local use of steroids or oral medications. ${ }^{9-13}$ We however included only those patients who did not receive any form of medical therapy prior to initial endoscopic procedure. Hence, it should be emphasized that awareness of unusual macroscopic distribution patterns, such as skip lesions, rectal sparing and backwash ileitis is important to avoid wrong subtyping of the inflammatory bowel disease.

Untreated UC in an active phase represents the prototypic diffuse active colitis. Biopsy specimens usually demonstrate a diffuse abnormality, meaning that the changes are of approximately the same intensity in all areas of the tissue. ${ }^{14}$ We observed diffuse active colitis in almost all cases (39, 97.5\%) although the degree of architectural distortion and degree of inflammation varied in different cases. One of the cases however showed focal active colitis. Clinical presentation, endoscopic findings and other histopathologic features favored ulcerative colitis over Crohn's Disease in this case. Diffuse active colitis though diagnostic of UC can also be seen in some examples of Crohn's colitis and in some cases of documented infectious colitis, although the latter could represent an infectious exacerbation of underlying latent primary inflammatory bowel disease. The diffuse active colitis pattern can also be seen in a form of colitis associated with diverticular disease; this entity is distinguished from classic UC by its rectal sparing and its presence exclusively in areas of diverticula. ${ }^{14}$

Focal active colitis refers to the patchy distribution of combined architectural change and inflammation in a mucosal biopsy specimen. The focal active colitis pattern consists of limited areas of increased inflammatory cells associated with focal architectural distortion; characteristically, some areas of the biopsy specimen maintain an essentially normal appearance. The focal active colitis pattern is usually not seen with UC, and, when it is present, suggests Crohn's colitis or infectious colitis and/or acute self-limited colitis. However, the focal active colitis pattern can be seen in resolving UC under medical treatment, and areas of previously inflamed colon and rectum in UC can return to an almost normal histologic appearance. ${ }^{14-16}$

Microscopic diagnosis of UC is based on widespread crypt architectural distortion, a diffuse transmucosal inflammatory infiltrate with basal plasmacytosis, eventually associated with an active component, causing cryptitis and crypt abscesses. Goblet cell depletion is less specific, but a helpful diagnostic feature. ${ }^{2}$ We observed variable degree of crypt architectural distortion in the form of crypt branching and budding and crypt atrophy. Various studies have shown distorted crypt architecture ranging from 


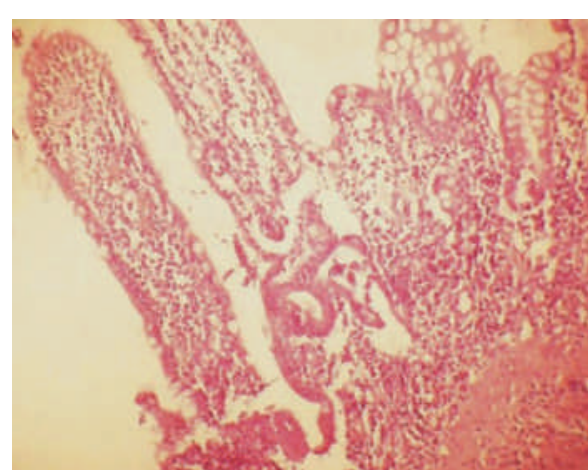

Figure 1: lleal biopsy showing backwash ileitis (HE stain, X100).

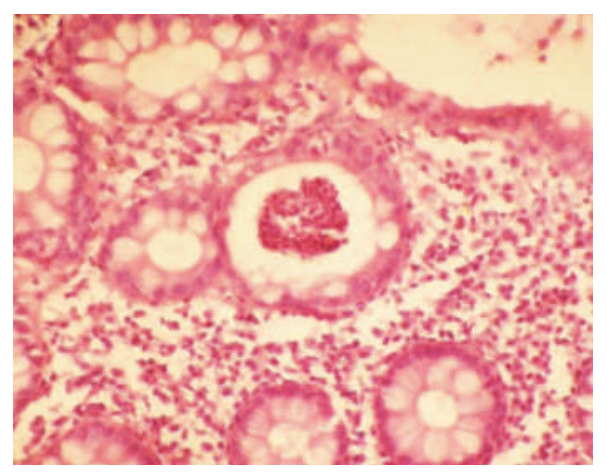

Figure 3: Rectal biopsy showing crypt abscess and diffuse lymphoplasmacytic infiltrate in the lamina propria (HE stain X400).

57 to $100 \%$ of cases. ${ }^{17-20}$ However in long standing cases restoration of architecture may result in a normal mucosa. ${ }^{14}$ We noticed normal crypt architecture in ten cases $(25 \%)$. The inflammatory infiltrate was composed of lymphocytes, plasma cells, neutrophils and eosinophils. Plasma cells are predominantly observed in between the crypts and the muscularis mucosae (basal plasmacytosis) which is the earliest diagnostic feature with the highest predictive value for the diagnosis of UC. ${ }^{14}$ In our study also, basal plasmacytosis was a constant feature (present in 34 cases). Basal plasmacytosis is helpful in the differentiation between a first attack of UC and infectious colitis, but not CD. Cryptitis as defined by presence of neutrophils within crypt epithelium and crypt abscesses defined by the presence of neutrophils within crypt lumina are features suggestive of active inflammation. ${ }^{14,17,19}$

Eosinophil infiltrate was prominent in 27 cases. There has been increasing evidence about the involvement of eosinophils in the pathogenesis of inflammatory bowel disease. Eosinophils play an important role as proinflammatory and pro-motility agents thus producing diarrhoea, tissue destruction and fibrosis. ${ }^{21}$

Inflammation may cause mucin depletion of the epithelium, a less diagnostic feature as it can also be found in infectious

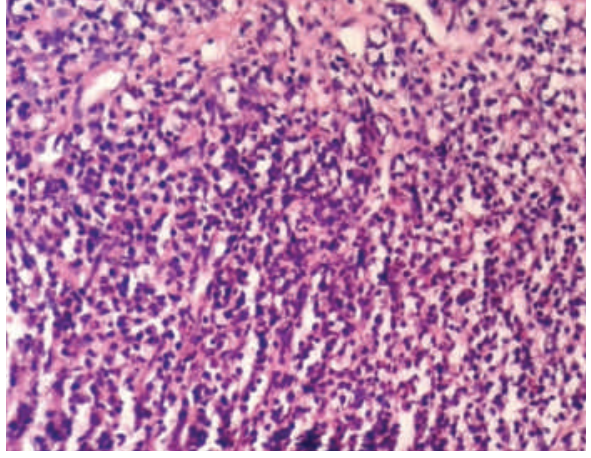

Figure 2. Colonic biopsy showing Basal plasmacytosis (HE stain, X400).

colitis and CD. We observed goblet cell depletion in 20 cases. Ajioka et al have reported that in the remission phase of ulcerative colitis inflammation is reduced and goblet cell mucus is reduced however evidence of past inflammation such as irregular crypts, paneth cell metaplasia and muscularis mucosa hypertrophy can still be appreciated. ${ }^{14,22}$

Preserved cryptarchitecture and the absence of a transmucosal inflammatory cell infiltrate do not rule out ulcerative colitis at an early stage. Le Berre et al. have shown that distorted crypt architecture with crypt atrophy, mucin depletion and cryptitis are features highly predictive of UC. Nevertheless features may change depending upon disease duration, patient's age and treatment. Hence it is recommended that rather than individual histomorphological features, combination of these changes need to be considered before giving the diagnosis of UC. ${ }^{2,23}$

Atypical presentation in UC is not uncommon. We noted one case with rectal sparing. Review of current literature reveals that in long standing disease the extent of gut involvement decreases with time ultimately leading to complete restoration of the rectal mucosa (rectal sparing) in 34 to $44 \%$ of patients. ${ }^{13,24}$ Our patient gave history of per rectal bleeding for 2 years before the first colonoscopy attempted, hence rectal sparing can probably be attributed to long history of ulcerative colitis.

One of the cases had pancolitis with involvement of ileum (backwash ileitis). It has been known that ulcerative colitis can spread to other portions of the gastrointestinal tract. Review of literature shows that ileum is involved in approximately one third of cases. This involvement is always in continuity with the colonic disease; it rarely spreads more than $10 \mathrm{~cm}$ away from Ileocaecal valve. ${ }^{25}$

In our study we observed only one case $(2.5 \%)$ showing low grade dysplasia. No invasive carcinoma was detected. Studies have shown colorectal cancer risk is associated with disease duration and disease extent and raises at the rate of approx. 0.5 to $1 \%$ per year after a total duration of colitis of 8 to 10 years. $^{26-28}$ The incidence of dysplasia or malignancy 
may appear lower in present study as we included only newly diagnosed cases. An elaborative study with regular follow up biopsies is required to understand the true risk for dysplasia or malignancy associated with ulcerative colitis.

\section{CONSLUSION}

Accurate diagnosis of UC requires elaborate knowledge of histological features. The histological findings should be correlated with clinical and endoscopic findings. Pathologists should also be aware of possible atypical presentation.

\section{Acknowledgement}

The authors would like to thank Dr. Namiko Hoshi, Assistant Professor, Department of Gastroenterology, Kobe University, Graduate School of Medicine, Kobe, Japan for her help while preparing this article.

\section{REFERENCES}

1. Geboes K. Histopathology of Crohns disease and Ulcerative colitis. Satsangi J, Sutherland LR, Colombel JF, Fiocci C, Lofberg R, Pemberton J, Rutgerts P, editors. Inflammatory Bowel Disease, Churchill Livingstone Edinburg, London, Melbourne; 2003.p.25576 .

2. Magro F, Langer C, Driessen A, et al. European concensus on the histopathology of inflammatory bowel disease. Journal of Crohns and colitis. 2013;7:827-51. Crossref

3. De Roche TC, Xiao SY, Xiuli L. Histological evaluation in ulcerative colitis. Gastroenterology Report. 2014:1-15

4. Dejaco C, Oesterreicher C, Angelberger S, et al. Diagnosing colitis: a prospective study on essential parameters for reaching a diagnosis. Endoscopy 2003;35:1004-8. Crossref

5. Surawicz CM. Serial sectioning of a portion of a rectal biopsy detects more focal abnormalities: a prospective study of patients with inflammatory bowel disease. Dig Dis Sci 1982;27:434-6.

6. Surawicz CM, Belic L. Rectal biopsy helps to distinguish acute self-limited colitis from idiopathic inflammatory bowel disease. Gastroenterology 1984;86:104-13. Crossref

7. Surawicz CM, Meisel JL, Ylvisaker T, Saunders DR, Rubin CE. Rectal biopsy in the diagnosis of Crohn's disease: value of multiple biopsies and serial sectioning. Gastroenterology 1981;80:66-71. Crossref

8. Tanaka M, Riddell RH, Saito H, et al. Morphologic criteria applicable to biopsy specimens for effective distinction of inflammatory bowel disease from other forms of colitis and of Crohn's disease from ulcerative colitis. Scand J Gastroenterol 1999;34:55-67. Crossref

9. Swan NC, Geoghegan JG, O'Donoghue DP, Hyland JM, Sheahan K. Fulminant colitis in inflammatory bowel disease: detailed pathologic and clinical analysis. Dis Colon Rectum 1998;41:1511-5. Crossref

10. Glickman JN, Bousvaros A, Farraye FA, et al. Pediatric patients with untreated ulcerative colitis may present initially with unusual morphologic findings. Am J Surg Pathol 2004;28:190-7. Crossref

11. Washington K, Greenson JK, Montgomery E, et al. Histopathology of ulcerative colitis in initial rectal biopsy in children. Am J Surg Pathol 2002;26:1441-9. Crossref

12. Joo M, Odze RD. Rectal sparing and skip lesions in ulcerative colitis: a comparative study of endoscopic and histologic findings in patients who underwent proctocolectomy. Am J Surg Pathol 2010;34:689-96. Crossref
13. Kim B, Barnett JL, Kleer CG, Appelman HD. Endoscopic and histological patchiness in treated ulcerative colitis. Am J Gastroenterol 1999;94:3258-62. Crossref

14. Petras RE, Gramlich TL. Nonneoplastic Intestinal Diseases. In: Mills SE, Carter D, Greenson JK, Reuter VE, Stoler MH, editors. Sternbergs Diagnostic Surgical Pathology, 5th Edition. Philadelphia: Lippincott Williams and Wilkins; 2010.p.1325.

15. Surawicz CM. Mucosal biopsy diagnosis of colitis. Semin Colon Rectal Surg 1992;3:154-9.

16. Odze R, Antonioli D, Peppercorn M, et al. Effect of topical 5-aminosalicylic acid (5-ASA) therapy on rectal mucosal morphology in chronic ulcerative colitis. Am J Surg Pathol 1993;17:869-75. Crossref

17. Seldenrijk CA, Morson BC, Meuwissen SGM, et al. Histopathological evaluation of colonic mucosal biopsy specimens in chronic inflammatory bowel disease: diagnostic implications. Gut 1991;32:1514-20. Crossref

18. Jenkins D, Balsitis M, Gallivan S, et al. Guidelines for the initial biopsy diagnosis of suspected chronic idiopathic inflammatory bowel disease. The British Society of Gastroenterology Initiative. J Clin Pathol 1997;50:93-105. Crossref

19. Surawicz CM, Haggitt RC, Husseman M, McFarland LV. Mucosal biopsy diagnosis of colitis: acute self-limited colitis and idiopathic inflammatory bowel disease. Gastroenterology 1994;107:755-63. Crossref

20. Theodossi A, Spiegelhalter DJ, Jass J, et al. Observer variation and discriminatory value of biopsy features in inflammatory bowel disease. Gut 1994;35:961-8. Crossref

21. Shah SN, Amarapurkar AD, Shrinivas N, Rathi PM. Atypical histological features of ulcerative colitis. Tropical Gastroenterology 2011;32:107-11. Crossref

22. Ajioka Y, Nishikura K, Watanabe G. Pathomorphology of ulcerative colitis. Nippon Risho. 2005;63:763-9. Crossref

23. Le Berre N, Heresbach D, Kerbaol M, et al. Histological discrimination of idiopathic inflammatory bowel disease from other types of colitis. J Clin Pathol 1995;48:749-53. Crossref

24. Kleer CG, Appelman HD. Ulcerative colitis - patterns of involvement in colorectal biopsies and changes with time. Am J Surg Pathol 1998;22:983-9. Crossref

25. Rosai J. Gastrointestinal tract. In: Rosai and Ackermans Surgical Pathology, 9th Edition. Elsevier; 2009.p.784.

26. Itzkowitz SH. Inflammatory bowel disease and cancer. Gastroenterol Clin North Am 1997;26:129-39. Crossref

27. Lashner BA, Silverstein MD, Hanauer SB. Hazard rates for dysplasia and cancer in ulcerative colitis. Results from a surveillance program. Dig Dis Sci 1989;34:1536-41. Crossref

28. Rutter MD, Saunders BP, Wilkinson KH, et al. Thirty-year analysis of a colonoscopic surveillance program for neoplasia in ulcerative colitis. Gastroenterology 2006;130:1030-8. Crossref 